\title{
DIMENSIÓN MISIONERA DEL PRESBÍTERO
}

DOI: https://doi.org/10.52039/seminarios.v59i208.255

Al hablar de la dimensión misionera del presbítero nos referimos a un elemento que va más allá de su condición de bautizado, que afecta a su identidad ministerial en una doble perspectiva: a) despertar y alimentar el protagonismo de su comunidad eclesial en la misión universal de la Iglesia; b) el sentido de que él mismo pueda recibir y desarrollar el carisma de la misión ad gentes; ambas perspectivas no deben ser vistas simplemente como desarrollo de la gracia bautismal sino como dinamismos del sacramento del orden.

Aparentemente, se trata de un tema secundario en el ministerio presbiteral, como un carisma que se añade a su vocación básica y que en definitiva le afecta a él personalmente y no al ministerio que ejerce en la Iglesia. Pero esta sería una visión muy estrecha y reducida. En realidad están implicadas cuestiones de mayor calado: el sentido mismo del presbítero en el Presbiterio de una iglesia local y la responsabilidad de esta en la misión universal de la Iglesia. La maduración de una iglesia local se puede medir por su autoconciencia como sujeto histórico en la misión de la Iglesia, lo cual va unido a su autoconciencia del Presbiterio y de su papel en la Iglesia. Ello no debe ser considerado de modo abstracto sino que tiene repercusiones patentes en la situación actual de la Iglesia (y de las iglesias): el dinamismo y la amplitud de su compromiso evangelizador. La profundización y la flexibilización de los marcos eclesiológicos dependen en gran medida de la atención que se presta a la dimensión misionera del presbítero en la doble perspectiva antes señalada: el dinamismo evangelizador en el entorno inmediato no puede separarse de la mirada universal, pues ambas dimensiones (como recordaba Juan Pablo II en Redemptoris missio) se exigen y se potencian recíprocamente.

Que este planteamiento no resulta evidente lo confirma una breve mirada a la historia. Aunque pueda resultar sorprendente, la dimensión misionera del presbítero resulta una adquisición relativamente reciente. Más aún: ha sido un logro (o un redescubrimiento) que ha implicado mucho esfuerzo y ha debido superar notables obstáculos. Conocer las dificultades de esos avatares históricos resulta

* Eloy Bueno de la Fuente, sacerdote de la Diócesis de Burgos. Catedrático de la Facultad de Teología del Norte de España (sede de Burgos). Enseña Cristología y Teoría del Conocimiento. 
necesario para captar el anquilosamiento al que pueden conducir determinadas sistematizaciones eclesiológicas, las cuales a largo plazo acaban teniendo consecuencias negativas en la vida concreta. Las prácticas eclesiales no son inocentes ni meras estrategias de funcionamiento sino que incluyen y ponen en evidencia los pilares fundamentales de la eclesiología y de la pastoral. Por ello lanzaremos una mirada al pasado para captar la inflexión que representa el Vaticano II, y así percibir los presupuestos teológicos que reclaman una nueva autoconciencia y unas nuevas prácticas eclesiales. Las urgencias y desafíos del presente sólo pueden afrontarse adecuadamente si se tienen en cuenta estos elementos.

1. LOS PRESBíteROS DIOCESANOS EN LA ACTIVIDAD MISIONERA DE LA IGLESIA: ENTRE LA PENUMBRA Y LOS TANTEOS.

Nuestro punto de partida será la época gloriosa de las misiones extranjeras a partir del siglo XVI. No sólo porque el inmenso esfuerzo que realizaron ha determinado el futuro de la Iglesia, sino porque en gran medida vivimos de las categorías teológicas y misionológicas sobre las que se desarrollaron ${ }^{1}$. En las últimas décadas se han dado cambios significativos, pero éstos no han penetrado de modo suficiente hasta los niveles que configuran el imaginario colectivo del pueblo cristiano y la espiritualidad de los presbíteros. Por ello resulta tan importante comprender adecuadamente la dimensión misionera del presbítero diocesano a la luz de la historia reciente, pues así se capta en lo concreto los estrechamientos que provoca una asunción ingenua y rutinaria de las prácticas eclesiales.

Los grandes descubrimientos geográficos del siglo XVI abrieron un escenario inmenso para el compromiso misionero de la Iglesia. Ante tal desafío se respondió de modo generoso y hasta heroico, con un éxito espectacular desde el punto de vista de la expansión de la Iglesia. Pero los protagonistas fundamentales, prácticamente exclusivos, fueron los religiosos. Órdenes y Congregaciones aportaron personas y recursos extraordinarios. Los presbiterios diocesanos, sin embargo, estuvieron prácticamente ausentes. Es un hecho, un dato contingente de la historia, pero con implicaciones enormes de cara al futuro: aunque no se perciba con claridad a primera vista, en la cuestión del presbítero está en juego la identidad de las iglesias locales (y por ello de la validez de la communio ecclesiarum).

A partir del siglo XVII la recién creada Propaganda Fide intentó equilibrar la situación. Deseaba coordinar (desde una autoridad central) todo el trabajo misionero. Con ello quería superar dos obstáculos: a) el control que los poderes públicos (sobre todo en España y Portugal) ejercían sobre sus misioneros, lo cual podía dificultar la libertad de la evangelización; b) los religiosos podían

1. Los presupuestos, implicaciones, grandezas y debilidades de este período (a la luz de los desarrollos posteriores) los he presentado en La Iglesia en la encrucijada de la misión, Verbo Divino, Estella 1999. 
caer en la tentación de primar los intereses de la propia institución en lugar de promover con decisión la creación de un clero nativo (en lo cual está implícito, aunque no se tematice, la iglesia local).

Para contrapesar tales riesgos, Propaganda Fide promovió la creación de un colegio misionero donde se formaran seminaristas con el compromiso de no ingresar en congregaciones religiosas. Así surgió en 1627 el Colegio Urbano (Urbano VIII asumía la iniciativa emprendida el año anterior por el español Juan Bautista Vives). No cuajó el intento de constituir un colegio semejante para sacerdotes.

Este laudable intento está condicionado desde su raíz por las circunstancias históricas y por la teología dominante. Así se explica la paradoja que debe ser objeto de especial atención: se pretende preparar sacerdotes seculares para «las misiones»; sin embargo, estos presbíteros no serán diocesanos (no serán miembros del Presbiterio de una iglesia local) sino dependientes de Propaganda Fide. Se acentúa la marginación y la pasividad de las iglesias locales: superadas por el dinamismo de las Congregaciones, quedan también ahora en la penumbra desde los proyectos de Propaganda Fide. La teología de la iglesia local y del presbiterio no estaban en aquella época en condiciones de reclamar otros planteamientos. Dominaba una eclesiología universalista (pero fundada en aspectos accidentales). El condicionamiento de ese presupuesto se percibe en el devenir de los fermentos innovadores que se irán abriendo camino entre tanteos.

En 1664 será reconocido por el Papa el Seminario de Misiones Extranjeras de París, que introduce una nueva figura de misionero: la de los Institutos misioneros seculares, es decir, aquellos cuyos miembros son sacerdotes seculares, pero incardinados en el Instituto.

El proyecto había surgido del deseo del clero y del laicado francés por participar en una empresa que parecía reservada a los religiosos. Asociaciones de devoción y de caridad salían al peso de las solicitudes de misioneros en Indochina. Aleteaba una intuición, casi profética, de futuro: se pretendía ante todo dar origen a un clero nativo que pudiera mantener las nuevas diócesis; para ello se nombró un grupo de vicarios apostólicos, dependientes de Propaganda, que desde ese Seminario contaran con los apoyos suficientes para consolidar la obra iniciada en el Lejano Oriente.

Como se ve, se insinúa una convicción clara: el futuro de la acción misionera depende de la constitución de diócesis, y por tanto de un grupo de presbíteros nativos que puedan permanecer en el lugar aun en momentos de persecución y que puedan acercarse con mayor facilidad a sus conciudadanos. Una intuición de futuro, pero lastrada por una peculiar paradoja. La paradoja surge porque se coloca el foco de atención en la diócesis de destino, pero no en la de origen: los vicarios apostólicos proceden del Seminario de Misiones Extranjeras a través de la legitimación de Propaganda Fide. El apoyo procede de asociaciones y grupos de devotos, no de las iglesias locales en sí. La dimensión universalista y unitaria de la Iglesia domina en la eclesiología de la época y en las prácticas eclesiales. 
El siglo XIX va a ser testigo de una sorprendente revitalización del movimiento misionero. Las convulsiones de la Revolución Francesa y las nuevas corrientes ideológicas habían socavado la infraestructura de la actividad misionera, que dejaba de contar con gran parte de los apoyos institucionales de los Estados. El aliento misionero decayó. No obstante el convulso siglo XIX generó un resurgir sorprendente, que se manifestó en multiplicidad de iniciativas. Los relatos de los misioneros y la compasión por la pobreza y la esclavitud suscitaron un sentimiento de caridad y de evangelización que penetró hondamente en el pueblo cristiano. Es la época en la que se van poniendo las bases de las futuras Obras Misionales Pontificias: gracias a iniciativas particulares (especialmente de laicos) los bautizados aportaron oraciones y subsidios económicos necesarios para la actividad misionera. Cuando disminuyen los apoyos de los poderes públicos el pueblo cristiano asume un claro protagonismo en la misión universal, si bien dentro de los marcos de la época. Adquiere protagonismo el conjunto de los bautizados, lo cual no significa que las diócesis o los presbiterios en cuanto tales se sientan responsables o protagonistas de aquella tarea.

Algunas asociaciones enviaron sacerdotes para desarrollar misioneros, pero como proyectos puntuales y particulares. No obstante se iban abriendo horizontes nuevos. Desde perspectivas diversas se buscaba cauces adecuados para la participación de sacerdotes en una actividad misionera en expansión: la creación de seminarios de misiones, el servicio de ultramar de presbíteros diocesanos para atender de modo especial a los colonos y colonizadores, cultivar la preocupación misionera en seminarios diocesanos... En esta dirección hubo realizaciones fecundas y prometedoras: en 1850 se abrió en Milán un seminario que expresara la apertura misionera de la Iglesia en Lombardía, en Verona (recogiendo la herencia de N. Mazza y el dinamismo de D. Comboni) se intentó una especie de «sociedad apostólica de vida en común sin votos» pero con reglas comunes.

Estas iniciativas vivían de un aliento sincero, que reflejaba la espiritualidad misionera del clero diocesano (e implícitamente de las diócesis), pero su realización concreta debió adecuarse a los marcos eclesiológicos y canónicos de la época: por ello acabaron dando origen a instituciones con capacidad de incardinación y por ello aproximándose a la configuración de los institutos religiosos. La idea de presbiterio y de diócesis sigue en la penumbra. El devenir de la configuración de estas nuevas instituciones, como los Combonianos, reflejan con claridad la fuerte tensión que procedía de los presupuestos teológicos: por un lado, el clero diocesano quería participar en la actividad misionera, pero, por otro, la inercia de la costumbre (o la urgencia de las necesidades) no permitieron la profundización y el despliegue de otros presupuestos profundamente tradicionales ${ }^{2}$.

2. He desarrollado esta problemática, en su contexto e implicaciones, en La iglesia local y el carisma ad gentes: realizaciones, posibilidades, incertidumbres, Estudios de Misionología 14, La vocación misionera específica y la iglesia local, Burgos 2009, 11-38. 
La misma dinámica se constata en España. Bajo la estela de los movimientos indicados, y con el deseo de recuperar el pasado misionero del país, se van abriendo también nuevos caminos. Los jesuitas de Oña (especialmente gracias a la figura de Hilarión Gil) intentaron desarrollar el potencial misionero de una Iglesia con cuarenta mil sacerdotes, y para ello sembraron la semilla en los seminaristas. Esta semilla se iría extendiendo por toda España, especialmente a través de las «academias misionales» o de una «liga misional de seminaristas». Incluso se empieza a rezar por la creación de un «seminario de misiones extranjeras» para el clero secular español (según el modelo de otros países).

En esta dirección se había ido ya desbrozando el camino. Gerardo Villota, sacerdote santanderino, posteriormente canónigo de Burgos, conocedor del Seminario de Misiones de París y de otras iniciativas semejantes, decidió contribuir al despertar de la dimensión misionera del clero diocesano ofreciéndole un cauce institucional. En su testamento (1896) decidió consagrar sus bienes a la creación de un Colegio Eclesiástico de Ultramar que pudiera desembocar en un auténtico Seminario de Misiones Extranjeras. Avanzando de modo humilde y a tanteos, debió afrontar enormes reticencias e incomprensiones (tanto del entorno inmediato como de Propaganda Fide). Entre la incertidumbre y el impasse, el proyecto resurgió con fuerza en 1919 gracias a la carta de Benedicto XV dirigida al arzobispo de Burgos, cardenal Benlloch, para que asumiera como prioridad la constitución de un Seminario de Misiones Extranjeras.

El tres de diciembre de 1920 se inaugura solemnemente rodeado de un enorme fervor misionero. Acompañado de un gran reconocimiento y apoyo nacional y local, se iría desarrollando durante las décadas siguientes. No obstante no se configuró explícita y directamente como expresión de la espiritualidad misionera del clero diocesano ni como dinamismo de las iglesias locales. Propaganda no aceptó las Constituciones que apuntaban en esa dirección. Exigió la excardinación de la propia diócesis y la incardinación en el Instituto, independiente del Ordinario del lugar y con personalidad jurídica propia. Se consolida como institución misionera, pero no consigue conjugar la relación intrínseca entre «presbiterio diocesano» y «compromiso misionero ad gentes». Estas limitaciones sólo quedarán superadas por el Vaticano II. Recogerá las semillas que se habían venido sembrando a lo largo de los siglos XIX y XX.

\section{HaCia EL VATICANo II}

La realidad de las comunidades cristianas que iban surgiendo gracias a la actividad de los misioneros imponía con mayor fuerza la necesidad del clero nativo (e, indirectamente, de la plantación de la Iglesia en nuevas regiones). Era la realidad que los Papas fueron presentando al conjunto de la Iglesia y de modo más inmediato a las congregaciones religiosas. El verdadero objetivo respondía a los datos más genuinos de la tradición de la Iglesia: los apóstoles desde el 
principio fueron anunciando el Evangelio y fundando iglesias. Pero ello no podía ser percibido con nitidez en aquellos momentos. Su verdadero significado y su auténtica realización requerían tiempo. Pero para ello hacía falta también que toda la Iglesia aportara su contribución. A ello van dirigidas de modo prioritario las encíclicas misioneras del siglo XX, en una lógica que se va prolongando en los distintos pontificados y que incluye la doble perspectiva que indicamos.

Benedicto XV publica con ese objetivo Maximum illud (1919). Se dirige a los obispos para estimularlos a colaborar en la tarea misionera de la Iglesia. Desde nuestro punto de vista nos interesa destacar un doble aspecto: a) es fundamental «organizar vuestro clero en punto de misiones»; dado que el pueblo cristiano ha mostrado su sensibilidad misionera, debe encauzarse adecuadamente ese fervor; b) es necesario que los sacerdotes alimenten entre los bautizados «el interés por la conversión de los gentiles» a fin de que colaboren con las iniciativas de las Obras Misionales Pontificas. Para que los presbíteros cumplan esta función se recomienda la instauración de la Unión Misional del Clero, creada con este fin (103-107).

Por otro lado, al hablar de las vocaciones específicamente misioneras contempla también a los presbíteros. Por ello pide a los obispos «fomentar la semilla de la vocación misionera, que tal vez empieza a germinar en los corazones de vuestros sacerdotes y seminaristas». Ante las reticencias o miedos que puedan despertar tales recomendaciones, observa: el hecho de que algunos sacerdotes se consagren a las misiones no debe ser valorado como una pérdida, sino que el Señor suscitará muchos y mejores sacerdotes (87-88).

Pío XI, en Rerum Ecclesiae (1926), prolonga la misma solicitud. Por lo que se refiere a la actividad pastoral habitual, exhorta a los sacerdotes para que recen y para que hagan rezar por las misiones, que prediquen sobre las misiones, que divulguen escritos de animación misionera, que fomenten las vocaciones misioneras, que tengan predilección por las Obras Misionales Pontificias (46-48). Asimismo recomienda fomentar entre los sacerdotes la vocación misionera ad gentes, pues (indica a los obispos) las necesidades de sus diócesis son mucho menores que las de los «paganos, sobre todo las que aún viven en la barbarie y sin civilización» (39-41).

Pío XII, en Fidei donum (1957), introduce una significativa inflexión, con enormes implicaciones eclesiológicas (aunque ni siquiera hoy se hayan sacado las consecuencias evidentes). Juan Pablo II reconocerá la «intuición profética» que superó «la dimensión territorial del servicio sacerdotal para ponerlo a disposición de toda la Iglesia» (Redemptoris missio 68). África en aquel momento estaba viviendo una encrucijada histórica: el proceso de descolonización y de autonomía política de muchos países podía provocar un rechazo del cristianismo, recibido del colonialismo occidental, y, como alternativa, abrir la puerta a las influencias del comunismo o del islam. Por ello Pío XII lanza un llamamiento a los sacerdotes del mundo entero para que ofrezcan algunos años de su ministerio 
a apoyar a las iglesias africanas en aquel difícil momento de transición (simultáneamente, y, es otro dato significativo, se solicitaba también la aportación de laicos especializados en campos como la educación o el desarrollo).

Esta invitación contó también con notables reticencias: se hablaba del peligro de la escasa preparación de los sacerdotes, de la seducción del «turismo eclesial», e incluso de confundir el ministerio sacerdotal con el servicio misionero. No obstante, la acogida que recibió contribuyó a desarrollar algunos aspectos importantes: los presbíteros diocesanos podían participar con pleno derecho en la misión ad gentes, el carisma ad gentes podía ser realizado durante algunos años, la catolicidad de la Iglesia debía vivirse como servicio de comunión entre iglesias, hay que responder a las necesidades históricas.

En los años anteriores en España surgieron iniciativas relevantes. Así, en la década de los cuarenta se desarrolla la «Misión Diocesana de Vitoria», a partir de las perspectivas abiertas por Ángel Sagarmínaga en un seminario floreciente: ¿por qué no se decidía la diócesis en cuanto tal, y por sí misma, a regir una misión o vicariato apostólico? La novedad se mostraba con claridad en la solicitud del obispo dirigida a las autoridades romanas: se entendía «como una expansión de la diócesis de Vitoria». Las reticencias de Propaganda fueron vencidas y se inició un nuevo camino: era la diócesis la protagonista, con la participación de laicos, pero igualmente con presbíteros que no debían renunciar a su incardinación (para insertarse en otro tipo de institución, según la idea de Propaganda).

En 1949 nace la Obra de Cooperación Sacerdotal Hispanoamericana (OCSHA), bajo los auspicios y dirección de la Conferencia de Metropolitanos españoles, como cauce ofrecido al empuje misionero de muchos presbíteros que deseaban prestar un servicio eclesial en América Latina. Su actividad no se dirigía prioritariamente a situaciones de primer anuncio, que consideraban reservada a Congregaciones o Institutos específicamente misioneros. Pero era clara su raíz diocesana: hubo de superar la sugerencia de Propaganda Fide de formar un Instituto al estilo del Instituto Español de Misiones Extranjeras. Se daban pasos significativos, pero las iglesias en cuanto tales seguían en la penumbra; en este caso la autoconciencia de los presbíteros iba por delante de la autoconciencia de las diócesis: los primeros sacerdotes actuaban movidos más por su impulso personal que por el de sus obispos o del presbiterio.

En todos estos casos se comprueba que el carisma de personas concretas iba abriendo los caminos del futuro, con intuiciones teológicas y espirituales que desbordaban los marcos jurídicos y teológicos de la época. Veían como una incongruencia que los presbíteros diocesanos no fueran protagonistas de la misión ad gentes y que tuvieran que reducirse a expresarlo en su oración o su ministerio pastoral. En esa opción novedosa pugnaba por abrirse camino una visión global de la eclesiología y del ministerio presbiteral que muy pocos percibían con nitidez. No hay más que vagos indicios de semejante tematización. Será el Vaticano II el que integrará tan ricas realizaciones concretas en una visión más amplia y global. 
3. LA INFLEXIÓN DEL CONCILIO VATICANO II: UNA MISIÓN UNIVERSAL CON MÚLTIPLES PROTAGONISTAS

El Concilio ofrece afirmaciones explícitas sobre la dimensión misionera del presbítero diocesano en la doble dirección ya indicada. Pero lo importante es que esas afirmaciones se producen en un marco eclesiológico renovado, que es el que legitima las afirmaciones concretas y el que reclama ulteriores desarrollos. Señalaremos las coordenadas principales, que son pilares de la arquitectura global del Vaticano II (la recíproca implicación de Iglesia y misión).

a) Tanto Lumen gentium como Ad gentes se abren con la presentación de «la Iglesia en el Misterio de Dios», que se despliega como el «espacio» de la misión del Hijo y del Espíritu Santo, a cuyo servicio se sitúa la misión de la Iglesia. La misión de la Iglesia, por tanto, es universal y, en consecuencia, todas sus actividades deben ser realizadas en la lógica de la revelación del Dios Trinidad.

b) El capítulo segundo de Lumen gentium, dedicado a la Iglesia como Pueblo de Dios (una de las novedades del Concilio), establece la igualdad fundamental de todos los fieles cristianos en base al bautismo; por ello se destaca la centralidad del sacerdocio bautismal, hasta el punto de que su efectivo ejercicio por parte de todos los bautizados es la finalidad a cuyo servicio se encuentra el sacerdocio ministerial. Ello significa que todo bautizado (también por tanto el presbítero) es corresponsable de la misión de la Iglesia en todas sus dimensiones y figuras (es significativo por ello que el mismo Vaticano II en Ad gentes reconocerá a los laicos como misioneros ad gentes, mientras que durante mucho tiempo la misionología los consideraba simplemente como «misioneros auxiliares»).

c) El realce dado al episcopado y a la colegialidad episcopal implica que sobre los obispos recae la solicitud por todas las iglesias y por la evangelización del mundo. Los obispos deben contribuir, pues, con aportaciones concretas de sus diócesis, para que la responsabilidad no quede en recomendaciones retóricas.

d) A lo largo del itinerario conciliar las diócesis (como iglesias locales) no aparecen en primer plano. Se podría decir que se habla de las diócesis al hablar de los obispos. A pesar de todo, sin embargo, se produjo un efectivo reconocimiento y redescubrimiento de las iglesias locales (o particulares), pues la Iglesia de Jesucristo existe en ellas y desde ellas. En consecuencia son sujetos históricos que deben expresar visiblemente la comunión con otras iglesias y la solicitud con sus proyectos evangelizadores. En Ad Gentes la identidad de las iglesias jóvenes se manifiesta con más nitidez: surgen de la acción misionera y deben asumir desde su nacimiento la responsabilidad en la evangelización universal (principio que debe valer también para las iglesias de vieja cristiandad).

Dentro de este nuevo planteamiento también el ministerio presbiteral experimenta una revalorización. No podemos entrar ahora en valorar logros e insuficiencias, pero hay afirmaciones que merecen nuestra atención. Baste recordar lo que afirman Lumen gentium, 28 y Christus Dominus, 28: «Los presbíteros... 
forman con su obispo un único presbiterio». En consecuencia sobre el presbítero debe recaer (aunque sea en el grado que le corresponde) la responsabilidad que recae sobre el obispo (sobre lo que volveremos más adelante).

Ad gentes 39, según la lógica indicada, explicita el deber misionero de los sacerdotes. Esta responsabilidad se debe desplegar en un doble nivel.

En su trabajo pastoral, «suscitarán y mantendrán entre los fieles el celo por la evangelización del mundo, instruyéndolos mediante la catequesis y la predicación sobre el deber de la Iglesia de anunciar a Cristo entre las gentes; educando a las familias cristianas sobre la necesidad y honor de cultivar las vocaciones misioneras entre sus hijos e hijas...». Deben, por ello, enseñar a los cristianos a rezar por las misiones y estimularlos a aportar su contribución económica.

El Decreto, en este número, no explicita su apertura al carisma de la misión ad gentes. Ello puede resultar comprensible dado que el número indicado se encuentra en el capítulo sexto, dedicado a la cooperación misionera; en este contexto la cooperación parece concebida esencialmente como la aportación que las iglesias de antigua cristiandad prestan a los misioneros que se hallan en tierras lejanas. No obstante, en el capítulo cuarto, dedicado a las vocaciones misioneras, se da por supuesta. El n. 23 afirma que la responsabilidad de propagar la fe incumbe a todo discípulo de Cristo si bien reconoce la existencia de una vocación específica: «Cristo Señor llama siempre de entre sus discípulos a los que quiere para que están con él y para enviarlos a predicar a las gentes»; en este grupo se incluyen «nativos o extranjeros, sacerdotes, religiosos laicos». Es curiosa y significativa la referencia a Mc 3,13 ss: se aplica a todos los bautizados, si bien el texto se refiere directamente a los Doce, a cuya luz hay que contemplar a los presbíteros (de un modo esencialmente distinto al de religiosos y laicos).

Dentro de esta lógica es comprensible que, hablando tanto de los seminaristas como de los presbíteros, se quiebre (en la línea de lo dicho por Juan Pablo II) una vinculación absoluta o unilateral entre ordenación y diócesis. Los seminaristas, dice el Vaticano II, deben formarse con «un espíritu genuinamente católico que los habitúe a mirar más allá de los límites de la propia diócesis, nación, rito y lanzarse en ayuda de las necesidades de toda la Iglesia» (OT 67). De modo más fuerte y directo afirma respecto a los presbíteros: «El don espiritual que los presbíteros recibieron en la ordenación no los prepara a una misión limitada y restringida, sino a la misión universal y amplísima de salvación hasta los confines de la tierra por ser participación de la misión que Cristo confió a los apóstoles» (PO 10). Estos elementos serán profundizados en la recepción postconciliar.

\section{EL DESARROLLO POSTCONCILIAR}

La reflexión suscitada por el Vaticano Il fue profundizando en el sentido de las iglesias locales y del presbiterio como presupuestos y estímulos para participar en la misión universal y en la vocación ad gentes. Ello provocó un repensamien- 
to y un replanteamiento de instituciones como el Instituto Español de Misiones Extranjeras. Desde sus orígenes había aceptado seminaristas procedentes de todas las diócesis de España, había excluido la incardinación en la propia diócesis de origen, e incluso habían aceptado laicos entre sus filas. «Parece que se empeñan en que seáis religiosos», les había dicho el rector Emilio Rodero como conclusión de sus negociaciones con Propaganda Fide de cara a fijar su estatuto canónico. Ahora había recursos teológicos para buscar una salida más fiel a sus orígenes fundacionales y carismáticos. Por ello parecía llegado el momento de dibujar su perfil como instrumento misionero del clero secular español. En consecuencia se suprime la presencia de laicos, se fomenta la incardinación en sus diócesis de origen, se busca la presencia en el presbiterio local, se cierra el seminario y se desarrollan las relaciones con la Conferencia Episcopal Española. En la VI Asamblea General de 1988 se definen como «asociación de sacerdotes diocesanos», "sociedad de vida apostólica de sacerdotes seculares españoles y candidatos al sacerdocio que se asocian entre sí para dedicarse a la actividad misionera de la Iglesia».

Juan Pablo II publica en 1990 Redemptoris missio para conmemorar el veinticinco aniversario de Ad gentes y para discernir la situación del fervor misionero y las nuevas urgencias y necesidades. Respecto a los presbíteros diocesanos repite textualmente las palabras ya mencionadas de Presbyterorum ordinis y Optatam totius, y proclama la validez permanente de Fidei donum. Por ello pide a los sacerdotes que estén disponibles al Espíritu Santo para ser enviados a predicar el Evangelio más allá de los confines del propio país; y asimismo expresa su deseo de que el espíritu de servicio aumente en el presbiterio de las iglesias antiguas y que sea promovido en el presbiterio de las iglesias más jóvenes (6768). Ser «antigua» o «nueva» resulta secundario respecto al dinamismo que brota de la iglesia local y del presbiterio.

La eclesiología de comunión y la teología del ministerio exigían la búsqueda de expresiones y realizaciones concretas y efectivas. Con esta intención la Sagrada Congregación para el Clero publicó la Instrucción Postquam Apostoli (25.3.1980), ofreciendo normas directrices para la colaboración entre las iglesias locales y específicamente para una mejor distribución del clero en el mundo. Las estadísticas de población y la desproporción de las fuerzas de apostolado interpelan a los datos teológicos para desactivar las reticencias sicológicas (la pérdida de efectivos de apostolado cuando crece la descristianización). El dinamismo interno de cada iglesia y su íntima comunión con otras iglesias reclama una colaboración y un intercambio de bienes que debe ser recíproca; los artífices de esta comunión en ejercicio deberán ser fundamentalmente los ministros, que deberán ser mensajeros de su propia comunidad y solidarios con los gritos que desde otras comunidades solicitan ayuda. La nueva perspectiva reclama una mayor flexibilidad de las estructuras eclesiales para salir al encuentro de las necesidades ajenas: para atender a turistas, para sustituciones en periodos va- 
cacionales, para atender a emigrantes... Aunque este documento no está pensado de modo exclusivo o prioritario para la actividad misionera resulta evidente que se le puede aplicar de modo claro, como hace el documento. De nuevo se confirma que lo decisivo debe ser una visión de la misión unida al ser mismo de la Iglesia, una experiencia concreta de la communio ecclesiarum y una visión dinámica del ministerio ordenado.

\section{Desde LA TEOLOGÍA QUE HOY NECESitAMOS}

Una mirada a la historia nos ha permitido comprobar que las prácticas eclesiales se van consolidando desde los datos teológicos recibidos de la Tradición pero moldeados por las circunstancias históricas y por las respuestas que se van dando por parte de la Iglesia. En este proceso se produce frecuentemente un estrechamiento que entra en tensión con otros aspectos o elementos que van siendo marginados. Estos pugnan por hacerse presentes, por encontrar espacio para su realización. En numerosas ocasiones este dinamismo acaba confirmándose como auténticamente genuino y tradicional, incluso más adecuado para afrontar los problemas pastorales de un contexto secularizado.

La actual experiencia eclesial, en la encrucijada e incertidumbres que la caracterizan, impone una doble coordenada que permita descubrir en toda su originalidad y dinamismo la dimensión misionera del presbítero diocesano:

a) En el actual proceso de globalización y mundialización resulta inevitable, como ha puesto de relieve Juan Pablo Il en los sucesivos Sínodos continentales, que la evangelización debe ser contemplada y considerada a nivel global; ello viene avalado (legitimado y exigido) por la experiencia de la catolicidad de la Iglesia como comunión de iglesias, como cuerpo de las iglesias; en consecuencia la evangelización en un mundo caracterizado por el pluralismo religioso (o irreligioso) no puede ser afrontada más que mediante el ejercicio concreto de la comunión entre todas las iglesias, aportando cada una sus riquezas y posibilidades.

b) Las iglesias de vieja cristiandad viven un proceso creciente de secularización (o de pluralismo religioso) en el que ya no existe una identificación entre la población y la Iglesia. Sólo algunos de los residentes en un lugar se identifican o reconocen como miembros de la Iglesia. Por todo ello el momento actual es ocasión privilegiada para re-descubrir a la diócesis como iglesia local, como la Iglesia de Jesucristo en un lugar. La teología de la iglesia local deja de ser un tema teológico abstracto para convertirse en experiencia de la propia fe integrada en un «nosotros» que se distingue de los conciudadanos. Lo que puede ser vivido como un peligro o una amenaza se transforma, desde los raíces de la revelación, en una posibilidad, en un camino, en definitiva en misión.

En estas circunstancias se puede comprender y se debe desarrollar la dimensión misionera del presbítero diocesano desde la identidad de la iglesia local y del presbítero. 


\section{La iglesia local: de la evangelización a la evangelización ${ }^{3}$}

La Iglesia no existe más que en y desde las iglesias locales concretas. El Vaticano II ha contribuido mucho para redescubrir las iglesias locales ${ }^{4}$. En la práctica se han realizado notables avances, pero a la vez no se pueda negar cierta sensación de bloqueo y de impasse. Para que la Iglesia se haga experiencia real es fundamental darse cuenta de que toda iglesia ha surgido y ha brotado gracias al anuncio del Evangelio por parte de alguien que ha venido de fuera aportando un testimonio novedoso.

El acontecimiento de Pentecostés marca el futuro de la Iglesia, porque debe ser actual en cada momento histórico. La Iglesia de Jesucristo se va a ir haciendo presente entre la pluralidad de los pueblos encarnándose en toda su variedad y diversidad. Las numerosas iglesias recrean la unidad de la familia humana porque introducen un elemento de reconciliación: el Evangelio y la Eucaristía superan y vencen las divisiones humanas.

Si cada iglesia nace del dinamismo de la evangelización no puede frenar su desarrollo, debe estar a su servicio. La Palabra que la convoca debe ser anunciada en otros lugares. Y ello es responsabilidad de cada iglesia. Hch 13, 1-3 ofrece un ejemplo paradigmático de esta autoconciencia que llega a realizaciones concretas. En Antioquia la ekklesía había sido convocada gracias a la Palabra que se expandió desde Jerusalén. En una de sus reuniones, ante el Señor en actitud de discernimiento comunitario, los cristianos constatan que la obra del Espíritu debe seguir adelante, y para ello se requieren personas concretas que asuman esa tarea en nombre de todos. En aquel caso fueron designados Pablo y Bernabé en función de la confluencia de tres actores: los creyentes que se ponen a disposición, el Espíritu que otorga el carisma, la comunidad entera que se ve prolongada en los apóstoles concretos; por eso les imponen todos las manos: para dar a entender que no van en nombre propio sino que asumen como responsabilidad personal lo que en realidad es tarea de la comunidad entera 5 .

Esta breve reflexión deposita ante nuestros ojos convicciones fundamentales para la experiencia eclesial: la dinámica evangelizadora de la que nació la Iglesia sigue siendo tarea permanente e ineludible, por lo que empuja a acercarse a los no creyentes, a los lugares donde no ha sido anunciado el Evangelio; ahora bien, la tarea de todos no puede ser realizada de modo idéntico por todos, sino que algunos en nombre de todos deben asumir determinados ministerios. También por tanto la misión ad gentes.

3. E. Bueno de la Fuente, Teología de la misión de la Iglesia, Instituto Internacional de Teología a Distancia, Madrid 1998, 76s.

4. E. Bueno de la Fuente - R. Calvo Pérez, La iglesia local, Madrid 2000.

5. E. Bueno de la Fuente, La misión en el dinamismo de comunión de la iglesia local, en Estudios de Misionología X, La misión de comunión, Burgos 2000, 235-258; La iglesia local, espacio de comunión para la misión, en "Es la hora de la misión». 57 Semana Española de Misionología, Burgos 2004, 37-64. 


\section{El presbitero en el presbiterio ${ }^{6}$}

La Iglesia y cada iglesia tienen una raíz -y por ello una estructura- apostólica. La apostolicidad no es idea o principio genérico sino realidad viva gracias a biografías concretas. Jesús llamó a Doce para que estuvieran con él y enviarlos a anunciar el Reino; ellos y algunos otros fueron constituidos como apóstoles en el acontecimiento pascual, como proclamadores y testigos de lo sucedido. Es un axioma teológico -y también histórico- que los apóstoles se dispersaron, fueron anunciando el Evangelio y fundando iglesias. Estas conservan su apostolicidad también en la medida en que se sitúan en la lógica de la sucesión apostólica. Y del testimonio que brota del acontecimiento pascual.

El presbítero no puede ser comprendido adecuadamente más que en ese preciso lugar. Cuando los apóstoles fueron muriendo las iglesias debían conservar su ministerio y su función: la episkopé, es decir, el ministerio de la inspección y de la vigilancia, como garantía y prolongación de la dimensión apostólica de la Iglesia y de cada iglesia.

El presbítero no puede ser comprendido simplemente desde su relación personal con el Cristo que lo llama y lo consagra, desde la relación a su comunidad concreta o desde la relación con su autoridad canónica. Como indica el Vaticano II, los presbíteros forman con su obispo un único presbiterio, dedicado a diversas tareas. Un único presbiterio como portador de la episkopé, en la cual se encuentra el obispo como su centro de comunión y presidente de la Eucaristía de la iglesia local. El presbiterio en consecuencia no es simplemente una yuxtaposición de presbíteros o una articulación para el funcionamiento o una estructura pastoral. El presbiterio tiene un carácter sacramental, constitutivo esencial de la iglesia local (sería un planteamiento abstracto, desgajado de la más antigua tradición, defender la existencia de un Presbiterio universal «por encima» de la radicación en una iglesia concreta); si este dinamismo se vive en el seno de la comunión de iglesias, es lógico que las iglesias agrupadas en una Conferencia Episcopal expliciten su vinculación especial con los misioneros de su contexto cultural (como hizo la Conferencia Episcopal Española en su 32 Asamblea de 1979).

Desde este presupuesto los presbíteros sirven a la unidad en la diversidad: desempeñan las diversas funciones no a título individual o como posesión propia, sino en nombre del presbiterio; sirven a los diversos carismas o grupos carismáticos en el seno de la iglesia con el fin de integrarlos en la comunión global, como expresión de la catolicidad y de la riqueza carismática de la iglesia. Pero ello no puede reducirse a la visión ad intra de la propia iglesia.

$\mathrm{Si}$, por tanto, la iglesia local tiene una apertura esencial a la misión ad gentes, no se puede decir menos del presbiterio. Y éste no sería fiel a la función sacramental que le corresponde si no expresara el compromiso con la misión univer-

6. E. Bueno de la Fuente, El presbiterio y la «episkopé»: Surge 51 (1993) 359-373. 
sal, también a través de alguno de sus miembros, que asume como propio y en nombre de todos lo que en realidad es responsabilidad del entero presbiterio ${ }^{7}$.

En su trabajo pastoral en la comunidad concreta que le es asignada corresponde al presbítero situar su vida y su ministerio en el horizonte de la misión universal, pues toda actividad eclesial adquiere su dinamismo del proyecto universal de salvación; en consecuencia tiene que promover la cooperación misionera no como la ayuda que se aporta a una responsabilidad que recae sobre otros, sino como el modo de co-laboración en la tarea que corresponde a todos.

En la vida concreta (especialmente a la luz de las circunstancias actuales) debe mostrar la fuerza interpeladora de la actividad misionera específica para discernir las «orillas» o «fronteras» que deben ser continuamente superadas para entrar en contacto con los otros, con los no cristianos que se sienten fuera de la Iglesia o del Evangelio; la misión ad gentes puede (debe) servir como paradigma para profundizar y dinamizar la pastoral ordinaria.

7. E. Bueno de la Fuente, Corresponsables en la misión, Instituto Internacional de Teología a Distancia, Madrid 1998, 50s. 